\title{
Linking social interdependence preferences to achievement goal adoption
}

\section{Article}

\section{Accepted Version}

Creative Commons: Attribution-Noncommercial-No Derivative Works 4.0

Elliot, A., J., Aldhobaiban, N., Kobeisy, A., Murayama, K., Gocłowska, M. A., Lichtenfeld, S. and Khayat, A. (2016) Linking social interdependence preferences to achievement goal adoption. Learning and Individual Differences, 50. pp. 291-295. ISSN 1041-6080 doi:

https://doi.org/10.1016/j.lindif.2016.08.020 Available at https://centaur.reading.ac.uk/66801/

It is advisable to refer to the publisher's version if you intend to cite from the work. See Guidance on citing.

To link to this article DOI: http://dx.doi.org/10.1016/j.lindif.2016.08.020

Publisher: Elsevier

All outputs in CentAUR are protected by Intellectual Property Rights law, including copyright law. Copyright and IPR is retained by the creators or other copyright holders. Terms and conditions for use of this material are defined in the End User Agreement.

\section{www.reading.ac.uk/centaur}

\section{CentAUR}


Central Archive at the University of Reading

Reading's research outputs online 
RUNNING HEAD: Social interdependence preferences

Linking social interdependence preferences to achievement goal adoption

Andrew J. Elliot ${ }^{1,2}$, Nawal Aldhobaiban ${ }^{2}$, Ahmed Kobeisy ${ }^{2}$, Kou Murayama ${ }^{3}$, Małgorzata A. Gocłowska $^{1,4}$, Stephanie Lichtenfeld ${ }^{5}$ \& Aber Khayat ${ }^{2}$

${ }^{1}$ University of Rochester, Department of Clinical and Social Sciences in Psychology, Rochester, NY, USA (andrew.elliot@ rochester.edu)

${ }^{2}$ King Abdulaziz University, Department of Psychology, Jeddah, Saudi Arabia (dohbaiban@hotmail.com, akobeisy@yahoo.com, Khayat@marshall.edu)

${ }^{3}$ University of Reading, Department of Psychology, Reading, UK (k.murayama@ reading.ac.uk)

${ }^{4}$ University of Amsterdam, Department of Psychology, Amsterdam, The Netherlands

(m.a.goclowska@ rochester.edu)

${ }^{5}$ University of Munich, Department of Psychology, Munich, Germany (lichtenfeld@psy.lmu.de)

Word count: 4032

Corresponding Author: Andrew Elliot

Acknowledgement: This project was funded by the Deanship of Scientific Research (DSR), King Abdulaziz University, Jeddah, under grant no. /1432/HiCi. The authors, therefore, acknowledge with thanks DSR technical and financial support. 


\begin{abstract}
Social interdependence theory and the $2 \times 2$ achievement goal framework represent two important literatures that are often studied independently. The present research examined general social interdependence attitudes in school (cooperative, competitive, and individualistic) as antecedents of individuals' situation-specific (semester- or class-focused) achievement goal adoption. All three studies consistently found that a cooperative attitude positively predicted mastery-approach goals, a competitive attitude positively predicted performance-approach and performance-avoidance goals, and an individualistic attitude positively predicted masteryapproach goals. The only anticipated relation that did not emerge consistently was that of an individualistic attitude as a positive predictor of mastery-avoidance goals. Implications of the present work for future empirical and theoretical development both in the social interdependence and the achievement goal literature are discussed.
\end{abstract}

Keywords: Social interdependence, competitive, cooperative, individualistic, achievement goals 


\section{Introduction}

Achievement goals -- competence-relevant commitments that guide individuals' behavior (Elliot, 1999) -- are central constructs in the achievement motivation literature. Achievement goals vary on two dimensions: how competence is defined (performance vs. mastery) and how competence is valenced (appetitive vs. aversive). When combined, these two dimensions create a $2 \times 2$ model comprising mastery-approach goals (trying to master a task or do better than before), mastery-avoidance goals (trying to avoid leaving a task unmastered or doing worse than before), performance-approach goals (trying to do better than others), and performance-avoidance goals (trying to avoid doing worse than others; Elliot, 1999; Pintrich, 2000).

A full and complete account of achievement motivation must not only attend to goals, but also the intrapersonal, interpersonal, and contextual antecedents of the goals (Elliot \& Thrash, 2001). These antecedents are posited to not only influence the adoption of achievement goals, but also to influence the way that achievement goal pursuit is experienced (Elliot, 2006). Many antecedents of achievement goals have been documented over the years, with the major focus being on competence-relevant antecedents (e.g., need for achievement, fear of failure, test anxiety, implicit theories of ability, perceived competence, and the way in which competence is evaluated in a given context; Baranik, Stanley, Bynum, \& Lance, 2010; Burnette, O’Boyle, VanEpps, Pollack, \& Finkel, 2013; Elliot, 1999; Payne, Youngcourt, \& Beaubien, 2007).

Achievement goals are commonly conceptualized as intrapersonal forms of selfregulation, but their adoption and pursuit is unequivocally social in nature. That is, achievement goals are often adopted with one's interpersonal relationships in mind, they are often pursued in the presence of others, and their attainment (or not) often has implications for one's interactions and relationships with, and one's standing relative to, others (Poortvliet \& Darnon, 2010; Ryan 
\& Shim, 2006; Tossman, Kaplan, \& Assor, 2008). Given this intertwining of social and achievement motivation, in the past decade researchers have called for and begun to conduct more and more research in this important area (for a review, see Darnon, Dompier, \& Poortvliet, 2012). The present research was conducted within this social-achievement motivation nexus, as we focused on general social interdependence attitudes toward school as antecedents of the adoption of the $2 \times 2$ achievement goals for specific semesters or classes.

Social interdependence is the degree to which the outcomes of an individual's actions influence those of others. Social interdependence can be high and positive leading to cooperation, high and negative leading to competition, or low leading to independence or individualism (Deutsch, 1949; Johnson \& Johnson, 2005). Individuals vary in their general attitudes toward each of these interdependence relations, and these attitudes have been shown to influence a variety of different achievement-relevant variables, such as effort, persistence, achievement, and transfer of learning (Johnson \& Johnson, 2005). Some existing research has linked general tendencies toward competitiveness to the adoption of situation-specific performance-approach and performance-avoidance goals (Murayama \& Elliot, 2012; Pastor, Barron, Miller, \& Davis, 2007). Other relevant research has linked situation-specific achievement goals to behavior within collaborative task settings (e.g., mastery-approach goals have been linked to cooperation with peers regardless of their group membership, whereas performance-approach goals have been linked to cooperation with ingroup peers and peers of high status; Levy, Kaplan, \& Patrick, 2004; see also Poortvliet, Ansel, Janssen, Van Yperen, \& Van de Vliert, 2012; Poortvliet, Janssen, Van Yperen, \& Van de Vliert, 2009; Tossman et al., 2008). Systematic research has yet to be conducted linking the three social interdependence attitudes -- cooperative, competitive, and individualistic -- to the adoption of achievement goals 
in specific situations.

Social interdependence attitudes, like other attitudes (Allport, 1935), encompass both valuation and liking components. A cooperative attitude represents a valuing of and a liking of working with others and helping others (Johnson \& Norem-Hebeisen, 1979). This attitude reflects a self-confidence and sense of security (Norem-Hebeisen \& Johnson, 1981; Ross, Rausch, \& Canada, 2003) that allows one to immerse oneself in tasks and self-improvement with minimal concern about the evaluation or performance of others (Nicholls \& Miller, 1994). As such, a cooperative attitude may be expected to positively predict mastery-approach goal adoption. A competitive attitude represents a valuing of and a liking of comparing oneself to others and performing better than others (Johnson \& Norem-Hebeisen, 1979). This attitude can reflect high but conditional self-acceptance (Norem-Hebeisen \& Johnson, 1981; Tjosvold, XueHuang, Johnson, \& Johnson, 2008) that is focused on norm-based evaluation. As such, a competitive attitude may be expected to positively predict both performance-approach and performance-avoidance goal adoption (see Murayama \& Elliot, 2012; Pastor et al., 2007). An individualistic attitude represents a valuing of and a liking of working by oneself and performing alone (Johnson \& Norem-Hebeisen, 1979). This attitude reflects an ability to think independently and creatively, but also a tendency toward self-criticism (Choi et al., 2011; Tjosvold et al., 2008). As such, an independence attitude may be expected to positively predict mastery-approach, but also mastery-avoidance goal adoption. Other links between social interdependence attitudes and achievement goal adoption may also emerge, but the aforementioned have the strongest and clearest conceptual grounding.

The present research comprises three studies focused on these relations between social interdependence attitudes and the adoption of the goals from the 2 x 2 achievement goal model. 
All studies contained the same core social interdependence and achievement goal variables, with variation in the specific focus of the achievement goals, the country in which the data were collected, and the temporal separation of the variables. In all studies we controlled for participant sex in analyzing the data to ensure that any observed relations were not simply a function of sex differences; in one study we controlled for socially desirable responding to ensure that any observed relations were not simply a function of response bias. Together, the results of these studies should afford a deeper and richer understanding of both social interdependence attitudes (i.e., evaluative dispositions) and achievement goals (i.e., intentional commitments), and will help further the process of integration of these two important literatures.

\section{Method}

\subsection{Participants and Procedure}

2.1.1. Study 1. 394 individuals ( 272 females, 120 males, 2 missing) completed the study voluntarily online on one of three sites: Research Match (61\%), Hanover College "Psychological Research on the Net" (37\%), and InMind (2\%). For Research Match, the age of participants was restricted to 18 -25 to maximize the likelihood that they would be university students (nonstudents were omitted from the data set a priori, resulting in a final $\mathrm{N}$ of 354). In the final sample, the mean age of participants was 22.32 years old; participants' ethnicity was $72 \%$ Caucasian, 5\% African-American, 10\% Asian, 5\% Hispanic, 8\% “Other/unspecified”. Participants completed the questionnaire during the months of November through April; the achievement goal measure focused on students' goals for the classes they were taking that semester.

2.1.2 Study 2. 333 undergraduates (246 females, 87 males) enrolled in psychology classes at a Saudi Arabian university participated in the study in return for extra course credit. The mean 
age of participants was 21.51 years old, and participants' ethnicity was 96\% Saudi, 2\% Asian, 1\% African, and 1\% "Other/unspecified". All measures were translated from English to Arabic (including back translation processes). Participants completed the questionnaire during the last month of the semester; the achievement goal measure focused on students' goals for the classes they were taking that semester. Thus, this study was more targeted than Study 1 in that all participants attended the same university and they reported on their goals during the same time of the semester.

2.1.3. Study 3. 340 undergraduates ( 214 females, 108 males, 18 missing) enrolled in a psychology class at a university in the U.S. participated in the study in return for extra course credit. The mean age of participants was 19.4 years old, and participants' ethnicity was $54.1 \%$ Caucasian, 26.2\% African-American, 5.3\% Asian, 8.2\% Hispanic, 6.1\% “Other/unspecified". The data for this study were collected in the context of a larger project; data from that project have been published in prior work (see Weidman, Tracy, \& Elliot, in press, Study 2c), but none of the variables used herein have been used in prior work. Participants completed the social desirability measure online the first week of the semester, the social interdependence attitudes measure online the second week of the semester, and the achievement goals measure online the third week of the semester; the achievement goal measure focused on students' goals for their psychology class. Thus, this study was more targeted than Study 2 in that all participants were in the same course and they reported their goals with respect to this course at the beginning of the semester. In addition, the social interdependence attitudes and achievement goals measure were separated in time, and a measure of social desirability was utilized in order to control for response bias.

2.2. Measures (see Table 1 for descriptive statistics, reliabilities, and intercorrelations) 
2.2.1. Social interdependence attitudes. The Social Interdependence Scales (Johnson \& Norem-Hebeisen, 1979) were used to assess participants' cooperative, competitive, and individualistic attitudes. Seven items assess cooperative interdependence (e.g., "It is a good idea for students to help each other learn", "I lke to cooperate with other students"), eight items assess competitive interdependence ("Competing with other students is a good way to work", "I like to be the best student in the class"), and seven items assess individualistic interdependence ("I do better work when I work alone”, "I would rather work on school work alone than with other students"). Participants responded on a 1 (not at all true of me) to 5 (extremely true of me) scale.

2.2.2. Achievement goals. The Achievement Goal Questionnaire-Revised (Elliot \& Murayama, 2008) was used to assess participants' 2 × 2 achievement goals for their class(es) (3 items per goal; the instructions for the measure set the specific [class or classes during the semester] focus: Mastery-approach (e.g., "My goal is to learn as much as possible;”), masteryavoidance (e.g., "My goal is to avoid learning less than it is possible to learn"), performanceapproach (e.g., "My goal is to perform better than the other students"), and performanceavoidance (e.g., "My goal is to avoid performing poorly compared to others"). Participants responded on a 1 (not at all [true for me]) to 5 (extremely [true for me]) scale.

2.2.3. Social desirability. The self-deceptive enhancement subscale of the Balanced Inventory of Desirable Responding (Paulhus, 1991) was used to assess social desirability. Participants responded on a 1 (not at all true) to 7 (very true) scale.

In all studies, no manipulations and no data exclusions were used, and all variables that were analyzed are reported. Sample sizes represent the maximum number of participants that could be recruited during the designated data collection period; all data were collected before any analyses were conducted. 


\section{Results}

In each study, we conducted multiple regression analyses to examine cooperative, competitive, and individualistic attitudes as simultaneous predictors of each of the achievement goals. In Study 3, we additionally conducted a second set of analyses with social desirability in the regression equations to control for participants' social desirability. In preliminary analyses, sex was included as a covariate in the equation and was retained when significant (all relations remained the same whether sex was included or excluded). Table 2 presents summaries of the regression results reported below for each study.

\subsection{Study 1}

Regressing each of the achievement goals on the three social interdependence attitudes yielded a significant model for each goal: mastery-approach $\left(R^{2}=.16, F(3,330)=20.79, p<\right.$ .001 , mastery-avoidance $\left(R^{2}=.03, F(3,327)=3.84, p=.010\right)$, performance-approach $\left(R^{2}=.49\right.$, $\mathrm{F}(4,331)=80.50, p<.001$, and performance-avoidance $\left(R^{2}=.29, F(3,333)=44.51, p<.001\right)$. A cooperative attitude was a positive predictor of mastery-approach goals $(\beta=.40, p<.001)$. A competitive attitude was a positive predictor of mastery-approach goals $(\beta=.20, p<.001)$, mastery-avoidance goals $(\beta=.12, p=.031)$, performance-approach goals $(\beta=.71, p<.001)$, and performance-avoidance goals $(\beta=.54, p<.001)$. An individualistic attitude was a positive predictor of mastery-approach goals $(\beta=.24, p<.001)$. Sex was a positive predictor of performance-approach goals $(\beta=.14, p<.001)$, indicating that females reported more performance-approach goal adoption than males.

\subsection{Study 2}

Regressing each of the achievement goals on the three social interdependence attitudes yielded a significant model for each goal: mastery-approach $\left(R^{2}=.26, F(4,328)=29.39, p<\right.$ 
.001 , mastery-avoidance $\left(R^{2}=.16, F(3,329)=21.58, p<.001\right)$, performance-approach $\left(R^{2}=.53\right.$, $\mathrm{F}(3,329)=122.73, p<.001$, and performance-avoidance $\left(R^{2}=.30, F(3,329)=46.55, p<.001\right)$. A cooperative attitude was a positive predictor of mastery-approach goals $(\beta=.33, p<.001)$ and mastery-avoidance goals $(\beta=.28, p<.001)$. A competitive attitude was a positive predictor of mastery-approach goals $(\beta=.27, p<.001)$, mastery-avoidance goals $(\beta=.18, p<.001)$, performance-approach goals $(\beta=.72, p<.001)$, and performance-avoidance goals $(\beta=.52, p<$ .001). An individualistic attitude was a positive predictor of mastery-approach goals $(\beta=.14, p=$ $.005)$ and mastery-avoidance goals $(\beta=.21, p<.001)$. Sex was a positive predictor of masteryapproach goals $(\beta=.13, p=.006)$, indicating that females reported more mastery-approach goal adoption than males.

\subsection{Study 3}

Regressing each of the achievement goals on the three social interdependence attitudes yielded a significant model for each goal: mastery-approach $\left(R^{2}=.08, F(4,314)=7.04, p<.001\right.$, mastery-avoidance $\left(R^{2}=.04, F(4,314)=3.57, p<.001\right)$, performance-approach $\left(R^{2}=.25, \mathrm{~F}(3\right.$, $314)=26.56, p<.001$, and performance-avoidance $\left(R^{2}=.06, F(4,314)=4.71, p<.001\right) . \mathrm{A}$ cooperative attitude wsa a positive predictor of mastery-approach goals $(\beta=.24, p<.001)$. A competitive attitude was a positive predictor of performance-approach goals $(\beta=.49, p<.001)$ and performance-avoidance goals $(\beta=.21, p<.001)$. An individualistic attitude was a positive predictor of mastery-approach goals $(\beta=.20, p=.002)$. Sex was a negative predictor of masteryapproach goals $(\beta=-.18, p=.002)$, mastery-avoidance goals $(\beta=-.18, p=.001)$, and performance-avoidance goals $(\beta=-.15, p=.009)$, indicating that males reported more masteryapproach, mastery-avoidance, and performance-avoidance goal adoption than females. Controlling for social desirability had no noteworthy influence on the observed relations (see 
Table 2).

\section{General Discussion}

Four relations between social interdependence attitudes and the achievement goals of the 2 x 2 model consistently emerged as statistically significant across the three studies: A cooperative attitude positively predicted mastery-approach goals, a competitive attitude positively predicted performance-approach and performance-avoidance goals, and an individualistic attitude positively predicted mastery-approach goals. Each of these relations was anticipated. The only anticipated relation that did not emerge consistently was that of an individualistic attitude as a positive predictor of mastery-avoidance goals; this link was observed in one sample and showed the same positive tendency in the two other samples, but was not strong enough to emerge consistently in terms of statistical significance.

Two other statistically significant relations were observed in two of the three samples: A competitive attitude was a positive predictor of mastery-approach goals, and a competitive attitude was also a positive predictor of mastery-avoidance goals. These relations suggest that specific task-/self-based goals may be used as concrete targets to guide and channel general other-based attitudes. This cross-standard, hierarchical regulation highlights the considerable variation in and flexibility of goal adoption and pursuit that has been largely overlooked to date in the achievement goal literature (Elliot, 2006).

Overall, the findings that emerged in our studies were quite similar across countries, and the country differences that were (descriptively) present were minor and not conceptually important. Nevertheless, if one carefully inspects the zero order correlations, one countryspecific pattern may be observed: A cooperative attitude was significantly positively related to a competitive attitude, mastery-avoidance goals, performance-approach goals, and performance- 
avoidance goals in Saudia Arabia only. This commingling of relatively other-focused, appetitive attitudes and motivation with relatively self-focused, aversive motivation in Saudia Arabia may be a reflection of the unique emphasis and valuing of both competition and collectivism in this culture (Hofstede, Van Hofstede, \& Minkov, 2010). Our research both heeds the call that has been sounded to expand the meager empirical base on achievement motivation in Gulf State countries (Moskovsky \& Alrabai, 2009), and suggests an interesting avenue for future investigation - the interplay of relatively "pure" and "impure" attitudes and motivational tendencies in achievement contexts in these cultures.

Two other observations on the obtained pattern of findings are worthy of brief note. First, the regression results for an individualistic attitude and mastery-approach goals was (descriptively) stronger than those for the zero order correlations, suggesting that one of the other social interdependence attitudes was serving as a suppressor variable. The likely candidate is a cooperative attitude, which was strongly negatively related to an individualistic attitude and positively related to mastery-approach goals. Second, as is sometimes the case with research on the $2 \times 2$ achievement goal model, the findings for mastery-avoidance goals tended to be (descriptively) weaker than those for the other goal constructs (although see Baranik, Lau, Stanley, Barron, \& Lance, 2013; Senko \& Freund, 2015).

A primary limitation of the present research is the exclusive use of self-report measures. The measures that we utilized are well-established operationalizations of the different constructs under investigation, but given their conceptual (and therefore operational) similarity in some instances (e.g., a competitive attitude and performance-based goals), future work would do well to extend these findings using social interdependence manipulations. A second limitation is that the present research was correlational in nature, thereby precluding causal inferences. It is quite 
possible that there are reciprocal relations between social interdependence attitudes and achievement goals. Both the aforementioned use of social interdependence manipulations and research specifically targeting the possibility of reciprocal relations between social interdependence attitudes and achievement goal pursuit would nicely attend to this issue. A third limitation is the focus on two countries only. Subsequent research would do well to expand to a broader and more diverse range of countries (e.g., incorporating the East/West distinction; see Dekker \& Fischer, 2008).

In conclusion, the findings from the present research afford a clearer portrait of both social interdependence and achievement goals. They show how general attitudes regarding selfother connections "work their way out" (see Nuttin, 1984) in the context of competence-relevant regulation in specific achievement settings. In addition, the present findings show that achievement goal adoption not only has roots in competence-based motivation, but also in social, relational motivation (see also Elliot \& Reis, 2003; Levy et al., 2004; Poortvliet \& Darnon, 2010; Tao \& Hong, 2014). Both types of constructs -- social interdependence and achievement goal -have considerable conceptual and predictive utility, and large literatures have developed around each. The present research furthers the integration of these lines of work in mutually beneficial fashion. 


\section{Footnotes}

1. Given that there is conceptual similarity among the competitive attitude and performanceapproach goal variables, and among the cooperative attitude and mastery-approach goal variables, we conducted ancillary confirmatory factor analyses (CFAs) in each study to test the separabilty of each pair of variables. We used $\chi^{2}$ difference tests, the AIC, the BIC, and the sample-adjusted BIC to determine whether the hypothesized two factor models (e.g., competitive attitude items load on one factor and performance-approach goal items load on a separate factor) or the alternative one factor models (e.g., competitive attitude items and performance-approach goal items load on the same factor) were a better fit to the data from CFAs with maximum likelihood estimation. In all instances, the $\chi^{2}$ difference test favored the two factor model (albeit only at $p=.064$ for a competitive attitude and performance-approach goals in Study 2).

Likewise, in all instances, the AIC and adjusted BIC values favored the two factor model (albeit only weakly for a competitive attitude and performance-approach goals in Study 2); the findings were the same for the BIC, only the weak findings for a competitive attitude and performanceapproach goals in Study 2 were equivocal (they favored the one factor model, but the difference in BIC was only 0.197). 


\section{References}

Allport, G. (1935). Attitudes. In C. Murchison (Ed.), A Handbook of Social Psychology (pp. 789844). Worcester, MA: Clark University Press.

Baranik, L. E., Lau, A. R., Stanley, L. J., Barron, K. E., \& Lance, C. E. (2013). Achievement goals in organizations: Is there support for mastery-avoidance? Journal of Managerial Issues, 25, 46.

Baranik, L. E., Stanley, L. J., Bynum, B. H., \& Lance, C. E. (2010). Examining the construct validity of mastery-avoidance achievement goals: A meta-analysis. Human Performance, 23, 265-282. doi:10.1080/08959285.2010.488463

Burnette, J. L., O’Boyle, E. H., VanEpps, E. M., Pollack, J. M., \& Finkel, E. J. (2013). Mind-sets matter: A meta-analytic review of implicit theories and self-regulation. Psychological Bulletin, 139, 655-701. doi.org/10.1037/a0029531

Choi, J., Johnson, D. W., \& Johnson, R. (2011). The roots of social dominance: Aggression, prosocial behavior, and social interdependence. The Journal of Educational Research, 104(6), 442-454. doi:10.1080/00220671.2010.514689

Darnon, C., Dompier, B., \& Poortvliet, M. (2012). Achievement goals in educational contexts: A social psychological perspective. Social and Personality Compass, 6, 760-771. doi.org/10.1111/j.1751-9004.2012.00457.x

Dekker, S., \& Fischer, R. (2008). Cultural differences in academic motivation goals: A metaanalysis across 13 societies. The Journal of Educational Research, 102, 99-110. doi:10.3200/JOER.102.2.99-110

Deutsch, M. (1949). A theory of cooperation and competition. Human Relations, 2, 129-152. doi:10.1177/001872674900200204 
Elliot, A. J. (1999). Approach and avoidance motivation and achievement goals. Educational Psychologist, 34, 169-189. doi:10.1207/s15326985ep3403_3

Elliot, A. J. (2006). The hierarchical model of approach-avoidance motivation. Motivation and Emotion, 30, 111-116. doi:10.1007/s11031-006-9028-7

Elliot, A. J., \& Murayama, K. (2008). On the measurement of achievement goals: Critique, illustration, and application. Journal of Educational Psychology, 100, 613-628. doi:10.1037/0022-0663.100.3.613

Elliot, A. J., \& Reis, H. T. (2003). Attachment and exploration in adulthood. Journal of Personality and Social Psychology, 85, 317-331. doi.org/10.1037/0022-3514.85.2.317

Elliot, A. J., \& Thrash, T. M. (2001). Achievement goals and the hierarchical model of achievement motivation. Educational Psychology Review, 12, 139-156. doi.org/10.1023/A:1009057102306

Hofstede, G., Van Hofstede, G., \& Minkov, M. (2010). From cultures and organizations: Software of the mind, $3^{\text {rd }}$ Ed. NY, NY: McGraw Hill.

Hulleman, C. S., Schrager, S. M., Bodmann, S. M., \& Harackiewicz, J. M. (2010). A metaanalytic review of achievement goal measures: different labels for the same constructs or different constructs with similar labels? Psychological Bulletin, 136, 422-449. doi:10.1037/a0018947

Johnson, D. W., \& Johnson, R. T. (2005). New developments in social interdependence theory. Genetic, Social, and General Psychology Monographs, 131, 285-358. doi:10.3200/MONO.131.4.285-358

Johnson, D. W., \& Norem-Hebeisen, A. A. (1979). A measure of cooperative, competitive, and individualistic attitudes. The Journal of Social Psychology, 109, 253-261. 
doi:10.1080/00224545.1979.9924201

Levy, I., Kaplan, A., \& Patrick, H. (2004). Early adolescents' achievement goals, social status, and attitudes toward cooperation with peers. Social Psychology of Education, 7, 127-159. doi.org/10.1023/B:SPOE.0000018547.08294.b6

Moskovsky, C., \& Alrabai, F. (2009). Intrinsic motivation in Saudi learners of English as a foreign language. The Open Applied Linguistics Journal, 2, 1-10. doi.org/10.2174/1874913500902010001

Murayama, K., \& Elliot, A. J. (2012). The competition-performance relation: A meta-analytic review and test of the opposing processes model of competition and performance. Psychological Bulletin, 138, 1035-1070. doi:10.1037/a0028324

Nichols, J. D., \& Miller, R. B. (1994). Cooperative learning and student motivation. Contemporary Educational Psychology, 19, 167-178. doi:10.1006/ceps.1994.1015

Norem-Hebeisen, A. A., \& Johnson, D. W. (1981). The relationship between cooperative, competitive, and individualistic attitudes and differentiated aspects of self-esteem. Journal of Personality, 49, 415-426. doi:10.1111/j.1467-6494.1981.tb00223.x

Nuttin, J. (1984). Motivation, planning, and action: A relational theory of behavior dynamics. Hillsdale, NJ: Lawrence Erlbaum.

Pastor, D. A., Barron, K. E., Miller, B. J., \& Davis, S. L. (2007). A latent profile analysis of college students' achievement goal orientation. Contemporary Educational Psychology, 32, 8-47. doi:10.1016/j.cedpsych.2006.10.003

Paulhus, D. L. (1991). Measurement and control of response bias. In J. Robinson, P. Shaver, \& L. Wrightsman (Eds.), Measures of personality and social psychological attitudes (pp. 17-59). San Diego, CA: Academic Press. 
Payne, S. C., Youngcourt, S. S., \& Beaubien, J. M. (2007). A meta-analytic examination of the goal orientation nomological net. Journal of Applied Psychology, 92, 128-150. doi:10.1037/0021-9010.92.1.128

Pintrich, P. R. (2000). An achievement goal theory perspective on issues in motivation terminology, theory, and research. Contemporary Educational Psychology, 25, 92-104. doi:10.1006/ceps.1999.1017

Poortvliet, P., M., Ansel, F., Janssen, O., Van Yperen, N., \& Van de Vliert, E. (2012). Perverse effects of other-referenced performance goals in an information exchange context. Journal of Business Ethics, 106, 401-414. doi.org/10.1007/s10551-011-1005-8

Poortvliet, P. M., \& Darnon, C. (2010). Toward a more social understanding of achievement goals: The interpersonal effects of mastery and performance goals. Psychological Science, 19, 324-328. doi.org/10.1177/0963721410383246

Poortvliet, P. M., Janssen, O., Van Yperen, N., \& Van de Vliert, E. (2009). The joint impact of achievement goals and performance feedback on information giving. Basic and Applied Social Psychology, 31, 197-209. doi.org/10.1080/01973530903058276

Ross, S. R., Rausch, M. K., \& Canada, K. E. (2003). Competition and cooperation in the fivefactor model: Individual differences in achievement orientation. The Journal of Psychology: Interdisciplinary and Applied, 137, 323-337. doi:10.1080/00223980309600617

Ryan, A. M., \& Shim, S. S. (2006). Social achievement goals: the nature and consequences of different orientations toward social competence. Personality and Social Psychology Bulletin, 32, 1246-1263. doi:10.1177/0146167206289345 
Senko, C., \& Freund, A. M. (2015). Are mastery-avoidance goals always detrimental? An adult development perspective. Motivation and Emotion, Advance online publication. doi:10.1007/s11031-015-9474-1

Tao, V. Y. K., \& Hong, Y.-y. (2014). When academic achievement is an obligation: Perspectives from social-oriented achievement motivation. Journal of Cross-Cultural Psychology, 45, 110-136. doi:10.1177/0022022113490072

Tjosvold, D., XueHuang, Y., Johnson, D. W., \& Johnson, R. T. (2008b). Social interdependence and orientation toward life and work. Journal of Applied Social Psychology, 38, 409-435. doi:10.1111/j.1559-1816.2007.00311.x

Tossman, I., Kaplan, A., \& Assor, A. (2008). Academic achievement goals structures and young adolescents' biased attitudes for peers as cooperation partners: A longitudinal study. Revue Internationale de Psychologie Sociale, 21, 181-215.

Weidman, A. C., Tracy, J. L., \& Elliot, A. J. (in press). The benefits of following your pride: Authentic pride promotes achievement. Journal of Personality. doi.org/10.1111/jopy.12184 
Table 1

Means, Standard Deviations, Reliabilities, and Correlation Coefficients for all Studies

\begin{tabular}{|c|c|c|c|c|c|c|c|c|c|c|}
\hline & $M$ & $S D$ & $\alpha$ & 1 & 2 & 3 & 4 & 5 & 6 & 7 \\
\hline 1. Coop & $3.49 / 3.30 / 3.99$ & $0.78 / 0.73 / 0.58$ & $.87 / 83 / .83$ & & & & & & & \\
\hline 2. Comp & $2.94 / 2.81 / 3.16$ & $0.99 / 0.87 / 0.74$ & $.87 / .83 / .83$ & $.00 / .40 /-.07$ & & & & & & \\
\hline 3. Indiv & $3.18 / 2.71 / 2.90$ & $1.00 / .0 .83 / 0.82$ & $.92 / .84 / .89$ & $-.61 /-.30 /-.55$ & $.20 / .02 / .08$ & & & & & \\
\hline 4. MAP & $4.01 / 3.78 / 4.00$ & $0.81 / 0.88 / 0.80$ & $.82 / .78 / .78$ & $.26 / .39 / .13$ & $. \mathbf{2 4} / . \mathbf{4 1} / .07$ & $.04 / .06 / .08$ & & & & \\
\hline 5. MAV & $3.35 / 3.11 / 2.95$ & $1.07 / 0.86 / 0.93$ & $.82 / .46 / .73$ & $.06 / .29 /-.01$ & $. \mathbf{1 4} / .30 / .04$ & $.07 / .13 / .06$ & $.54 / .50 / .32$ & & & \\
\hline 6. PAP & $3.41 / 3.21 / 3.66$ & $1.15 / 1.10 / 0.98$ & $.86 / .85 / .87$ & $-.01 / .31 /-.05$ & $.69 / .73 / .49$ & $.11 /-.01 / .00$ & $.26 / .49 /-.02$ & .18/.32/-.07 & & \\
\hline 7. PAV & $3.44 / 3.64 / 3.37$ & $1.05 / 1.08 / 1.07$ & $.89 / .82 / .83$ & $.01 / .28 /-.04$ & $.53 / .54 / .17$ & $.08 /-02 / .04$ & $.12 / .43 /-.13$ & $.34 / .31 / .19$ & $.74 / .75 / .51$ & \\
\hline 8. SocD & $--/--/ 4.06$ & $--/--/ 0.60$ & $--/--/ .69$ & $--/--/ .16$ & $--/--/-.01$ & $--/--/-.06$ & --/--/-.02 & $--/--/ .01$ & --/--/-.04 & --/--/-.08 \\
\hline
\end{tabular}

Note: Coop $=$ cooperative preferences, Comp $=$ competitive preferences, Ind $=$ individualistic preferences, $\mathrm{MAP}=$ mastery-approach goals, MAV = mastery-avoidance goals $\mathrm{PAP}=$ performance-approach goals, $\mathrm{PAV}=$ performance-avoidance goals, $\mathrm{SocD}=\mathrm{social}$ desirability, S1 = Study 1, S2 = Study 2, S3 = Study 3. Coefficients with $p<.05$ (two-tailed) are printed in bold. 
Table 2

Standardized Regression Coefficients from Simultaneous Regression Analyses for all Studies

\begin{tabular}{|c|c|c|c|c|c|c|c|c|c|c|c|c|}
\hline & \multicolumn{3}{|c|}{ MAP } & \multicolumn{3}{|c|}{ MAV } & \multicolumn{3}{|c|}{ PAP } & \multicolumn{3}{|c|}{ PAV } \\
\hline Comp & $.20 * *$ & $.27 * *$ & $.10 / .10$ & $.12 *$ & $.18^{* *}$ & $.08 / .08$ & $.71 * *$ & $.72 * *$ & $.49 * * / .51 * *$ & $.54 * *$ & $.52 * *$ & $.21 * * / .21 * *$ \\
\hline Indiv & $.24 * *$ & $.14 * *$ & $.20 * * / .20 * *$ & .13 & $.21 * *$ & $.11 / .10$ & -.09 & -.02 & $-.06 /-.06$ & -.05 & -.01 & $.04 / .03$ \\
\hline
\end{tabular}

Note . Coop = cooperative preferences, comp = competitive preferences, Indiv = individualistic preferences, SocD = social desirability;

MAP = mastery-approach goals, MAV = mastery-avoidance goals, $\mathrm{PAP}=$ performance-approach goals, $\mathrm{PAV}=$ performance-

avoidance goals, $\mathrm{S} 1$ = Study 1, S2 = Study 2, S3 = Study 3. Tabled values are standard coefficients from simultaneous regression analyses; sex is controlled when significant. Standardized regression coefficients for Study 3 are displayed for analyses controlling / not controlling for social desirability. $* p<.05, * * p<.01$. 